\section{LATE BRONZE AGE STRUCTURE (AREA D)}

This area, similar to Area F, did not command a vantage point on top of a hill like the other areas, but occupied a position on a gentle slope. The subsoil generally comprised sandy silt with medium-sized stones throughout. The northern area of excavation had a higher clay content and was less well drained. The excavation returned radiocarbon dates indicating a LBA date. There was a single unenclosed post-built structure, $1 \mathrm{D}$, with an entrance framed by a porch that faced the south-east (Illus 48). There were a few internal pits within the structure. Other features external to the structure included the possible remnants of a land boundary to the north-west and a group of small pits to the south-east.

\subsection{Structure 1D}

Structure 1D was defined by a ring groove with a diameter of $11.5 \mathrm{~m}$ which was truncated into seven segments (020, 084, 064, 029, 056, 023 and 031), and which ranged in size from $0.25 \mathrm{~m}$ by $0.3 \mathrm{~m}$ by

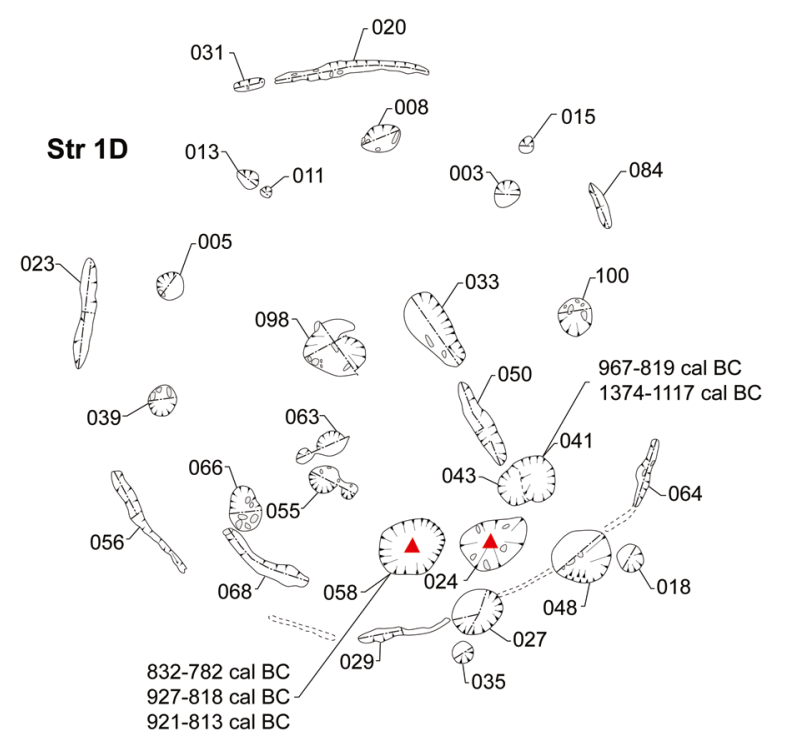

- Feature containing pottery

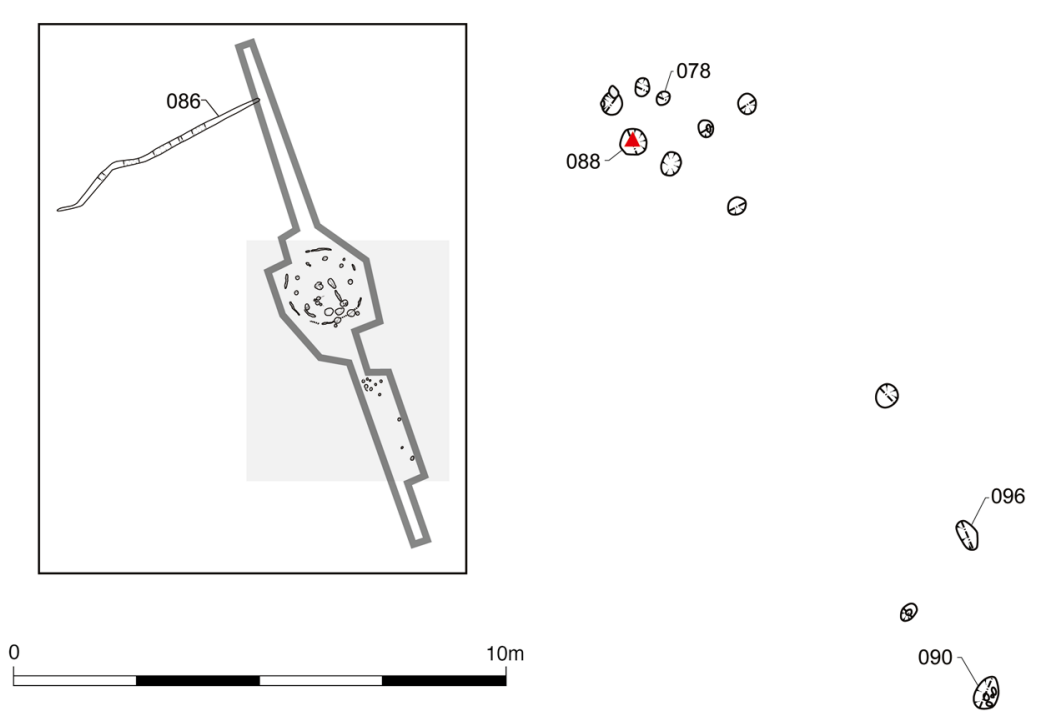

Illus 48 Plan of Area D 
$0.1 \mathrm{~m}$ deep, to $0.2 \mathrm{~m}$ by $2.35 \mathrm{~m}$ by $0.14 \mathrm{~m}$ deep. The segments of the ring groove were filled with sandy silts. No post holes were identified within the feature although Post Hole 015 fell within its projected north-eastern arc. The truncated remains of another curvilinear feature (068) were recorded in the south-west quadrant of the house. Either of these features may have been the remains of the foundation for an outer wall.

Structure 1D had a post ring of $c 8.5 \mathrm{~m}$ diameter made up of nine sub-circular post holes, spaced fairly regularly at $c 2 \mathrm{~m}$ apart, running internally concentric with the ring groove $(008,003,100$, $041 / 043,058,066,039,005$ and 013) at a distance of $c 1.8 \mathrm{~m}$ from it. Three contained packing stones (005, 039 and 100 Illus 49a). These post holes ranged in size from $0.34 \mathrm{~m}$ diameter by $0.05 \mathrm{~m}$ deep to $1.1 \mathrm{~m}$ by $1.35 \mathrm{~m}$ and $0.37 \mathrm{~m}$ deep. With the exception of Post Hole 008, which had two fills, they each contained single fills of sandy gravels and silt, black-grey and brown in colour. A possible post-pipe impression was recorded in Post Hole 100 (Illus 49a). Given their small size, proximity and similar fills, Post Holes 011 and 013 may have been the irregular base of a single truncated post hole or evidence of replacement.
The entrance faced the south-east, and was defined by four large post holes, 048, 027, 058 (Illus 49c) and 041 (Illus 49b), with 043 possibly acting as a replacement or shoring for 041 . Two further post holes, 018 and 035, defined the outer entrance in a similar way to those seen in Structure 1F (Section 8). Within the entrance was a paving stone, 024 , which had been laid over a depression in the subsoil. This depression had become filled with a charcoal-rich grey silty deposit which may relate to material accumulated during the occupation of the house. Three small sherds of pottery were recovered from this feature, and a further six came from Post Hole 058 (see Section 8.4.1).

There were a few internal features varying in size from $0.2 \mathrm{~m}$ diameter by $0.15 \mathrm{~m}$ deep to $0.9 \mathrm{~m}$ by $1.2 \mathrm{~m}$ by $0.27 \mathrm{~m}$ deep. Although 098 and 033 (Illus 49d) occupied near-central positions in the structure and one or both could represent the remains of a hearth, there was no evidence of in-situ burning within either of their fills. A small linear cut, 050, aligned between the porch post hole (041) and the pit (033), may have been a foundation for an internal division.
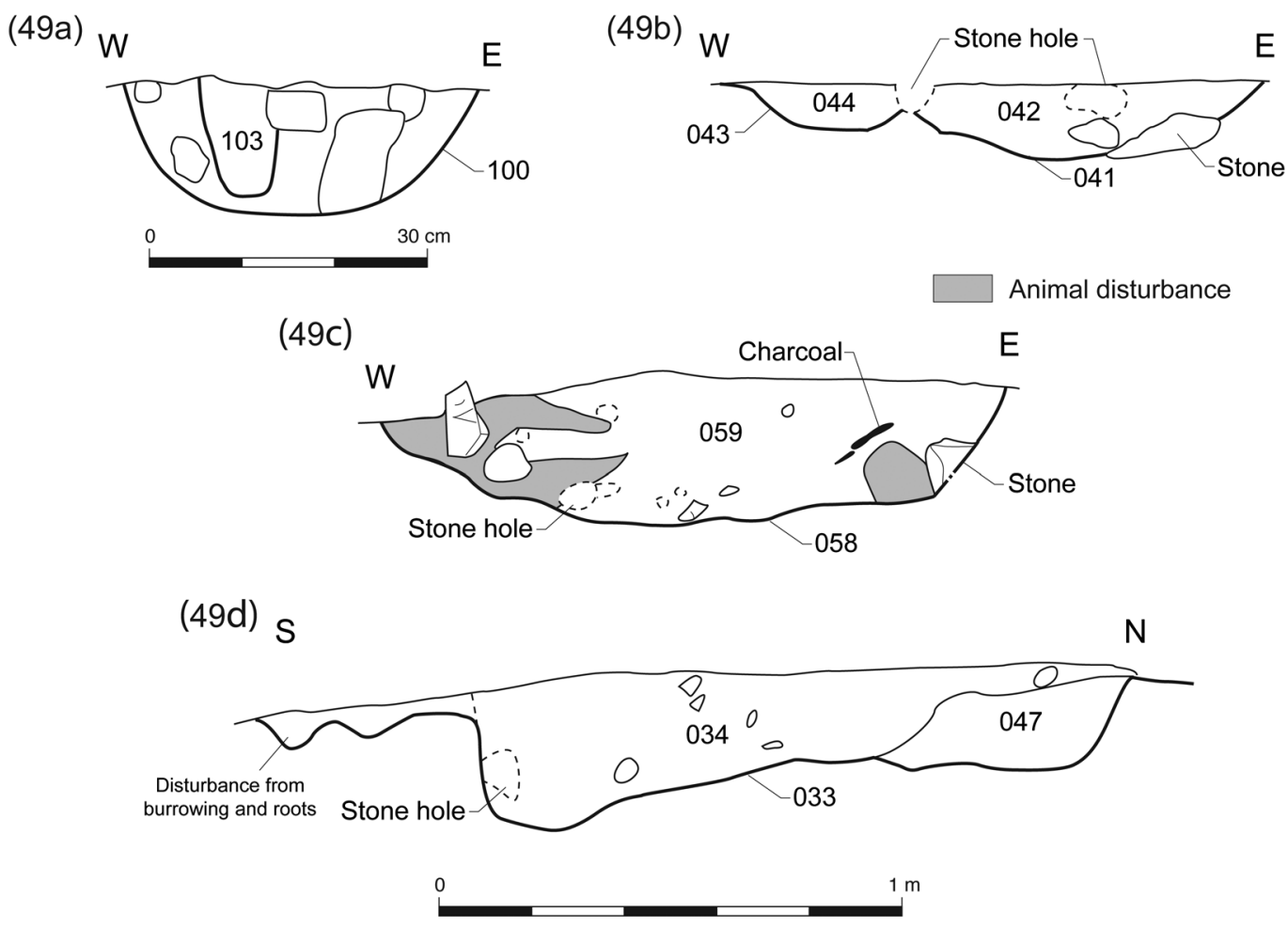

Illus 49 Selected sections, Area D 


\subsubsection{Interpretation and phasing}

There appears to be at least one phase to this post ring structure, although Curvilinear Feature 068 may represent another. However, with the exception of a probable replacement Post Hole 043, replacing 041, which was likely a running repair, there was no other stratigraphic or artefactual evidence to suggest more than one phase of building. Its size and appearance in plan are very similar to Structure 1F.

\subsection{Other features}

\subsubsection{Pits to the south-east of Structure 1D}

There was a group of eight small pits to the southeast of Structure 1D which varied in size from $0.2 \mathrm{~m}$ by $0.3 \mathrm{~m}$ by $0.04 \mathrm{~m}$ deep to $0.43 \mathrm{~m}$ by $0.5 \mathrm{~m}$ by $0.23 \mathrm{~m}$ deep. Pottery, representing two vessels, was recovered from Pit 088 (see Section 9.3.1 below), and there were tiny fragments of burnt bone in three of the features.

Further to the south-east there were another four isolated features, of which 090 and 096 aligned with a modern fence which is still standing to the north-west of the site. With the exception of 090 and 096, the function of these features is unknown.

\subsubsection{Linear feature}

An irregular linear feature, 086, aligned north-east/ south-west, was excavated some $20 \mathrm{~m}$ to the north of Structure 1D, with its north-east end extending into

Table 16 Pottery from Area D

\begin{tabular}{lllrr} 
ID & Cut & Feature & No. & Wt (g) \\
P137 & 024 & Str 1D & 3 & 5 \\
\hline P138 & 058 & Str 1D & 1 & 7 \\
\hline P139 & 058 & Str 1D & 3 & 7 \\
\hline P140 & 058 & Str 1D & 2 & 16 \\
\hline P141 & 088 & External & 9 & 52 \\
\hline P142 & 088 & External & 7 & 44 \\
\hline P193 & & Unstrat. & 1 & 7 \\
\hline P194 & & Unstrat. & 2 & 12 \\
\hline P195 & & Unstrat. & 2 & 21 \\
\hline Total & & & 30 & 171
\end{tabular}

Area D (Illus 48); this was found within Evaluation Trenches 198 and 199. The cut of the feature could be seen in plan and its depth determined by evaluation slots. It measured $15 \mathrm{~m}$ by $0.5 \mathrm{~m}$ by $0.3 \mathrm{~m}$ deep and was filled with two silt deposits. The linear feature is associated with Structure 1D by proximity only. No post holes were seen in plan or in the excavated sections, although the possibility that post holes were present in unexcavated sections cannot be ruled out. The feature followed the undulations in the subsoil, precluding it from being a drainage channel where a constant negative gradient would be required. The function and date of this feature have not been established, however, possibilities could include some form of boundary, either the foundations for a fence or, given its sinuous nature, the remnants of a hedge line.

\subsection{Artefacts}

\subsubsection{Pottery}

\section{Melanie Johnson}

A very small assemblage (30 sherds) was recovered from this area, with very little diagnostic material (Table 16).

Nine sherds from five different vessels came from contexts associated with Structure 1D. These came from just two pits, 024 and 058 , both lying at the surmised entrance porch in the south-east of the structure. Only one of the vessels (P139) had any diagnostic traits, comprising two very small rim sherds; these have a rounded tip, but very little of the profile of the vessel survives. They were $7 \mathrm{~mm}$ thick, brown in colour and with a lightly gritted fabric. The other vessels were all represented by plain body sherds, tending to be very abraded with gritty fabrics.

A further 16 sherds were recovered from Pit 088, one of a small cluster of pits lying to the south-east of the structure. These were from two different vessels and comprised plain body sherds, with a single curved sherd from P142 suggesting part of a base. The sherds from both vessels were abraded and small in size, with sandy fabrics, smoothed surfaces and sooting present on the interior.

Five sherds were recovered during general cleaning of the site and so are unstratified. These are all plain body sherds with gritty fabrics. 


\subsection{Environmental evidence}

\subsubsection{Calcined bone}

Sue Anderson

With the exception of $0.2 \mathrm{~g}$ recovered from three features in the pit group to the south-east of Structure 1D and $0.4 \mathrm{~g}$ from Pit 033 inside the structure, all fragments were associated with structural features of Structure 1D $(9.2 \mathrm{~g})$. The majority of pieces were recovered from the porch area, perhaps indicating that they were deposited during floor sweeping or other cleaning activities. Identifiable fragments were all non-human.

\subsubsection{Charcoal}

Michael Cressey

With only two species represented, Area D is extremely poor, with only 14 identifiable fragments, weighing $1.9 \mathrm{~g}$ in total, of which oak formed the majority (10 identifications, $1.8 \mathrm{~g}$ ), the remainder being hazel. The fragments were recovered from Pit 063 within Structure 1D, and Pit 078 in the group to the southeast. This assemblage was dominated by very small fragments well below the level of identification.

\subsubsection{Charred grain \\ Mhairi Hastie}

Thirty-five samples were assessed from features in this area, of which 27 were associated with Structure 1D, the remainder being from pits to the south. Samples from five post holes were sterile, and most of the rest produced only small quantities of grain. The largest group was recovered from Pit 033 (Table 17).

Both barley and wheat were identified. Some of the grains of barley still had apparent hulls attached, indicating that the hulled variety was present. Hulled barley was not identified in any other excavated area. Although preservation of the wheat grains was generally poor, both spelt and emmer wheat were identified (in Post Holes 055 and 039 respectively). Chaff remains, which would allow a definite identification of the wheat species, were not present. One small indeterminate culm node (straw fragment) and a few fragments of hazelnut shell were also present. Only one sample from this area contained any weed seeds, Pit 033 . Weed seeds present include brome/rye grass (Bromus/Lolium sp.) and ribwort. In addition, it is thought that the small quantity of possible rye grains recovered from this sample are also weed seeds of the barley crop (see Section 11.5.2).

The presence of hulled barley fits in well with the LBA/EIA dates for the features in this area. The hulled variety of barley was the most common cereal in Scotland during the Iron Age after it widely replaced the naked variety. It is thought that this may be a response by farmers to climatic decline during this period. The hulled barley grains

Table 17 Composition of plant remains from Pit 033

\begin{tabular}{|c|c|c|c|}
\hline Latin name & Plant part & Common name & Quantity \\
\hline \multicolumn{4}{|l|}{ Weed seeds } \\
\hline Plantago lanceolata L. & Seed & Ribwort & 1 \\
\hline Bromus/Lolium sp. & Caryopsis & Brome/rye grass & 2 \\
\hline \multicolumn{4}{|l|}{ Cereals } \\
\hline Triticum sp. & Caryopsis & Wheat & 1 \\
\hline cf Triticum sp. & Caryopsis & Wheat & 1 \\
\hline Hordeum var. vulgare (TW) & Caryopsis & Hulled barley & 6 \\
\hline Hordeum var. vulgare (ST) & Caryopsis & Hulled barley & 4 \\
\hline Hordeum var. vulgare & Caryopsis & Hulled barley & 11 \\
\hline Hordeum sp. & Caryopsis & Barley & 9 \\
\hline cf Secale cereale & Caryopsis & Rye & 10 \\
\hline Cereal indet. & Caryopsis & Indeterminate & 18 \\
\hline
\end{tabular}


are enclosed in fused grains that would have given better protection from damp and fungal attack compared to the naked, free-threshing variety (Ramsay 2009).

\subsection{Radiocarbon dating}

Five radiocarbon dates were obtained from material retrieved from the fills of the entrance Post Holes 058 and 041 (Table 18; Illus 50). It is possible that the material became entrapped by the porch posts as the house was being swept out, and thus the dates reflect the structure's period of occupation.

The three dates returned from Post Hole 058 were statistically different, but two dates (UBA-13326 and UBA-13327) passed the chi-squared test and therefore can be combined giving an average age range of 924-815 cal BC. The two dates returned from Post
Hole 041 were also statistically different. However, three dates from the two contexts (UBA-13323, UBA-13326 and UBA-13327) were not statistically different and suggest that the structure probably belonged in the 9th or later 10th centuries BC. The presence of hulled barley also supports a probable LBA date of activity (see Section 9.4.3, Hastie, above).

The date returned from Sample <UBA-13324> probably reflects residuality of the hazelnut shell, and the wheat from Post Hole 058 was potentially later than the main period of structure use.

\subsection{Discussion}

\subsubsection{Phasing}

There were no stratigraphic relationships and little artefactual evidence to aid in phasing of the main features. Therefore it cannot be ascertained whether

Table 18 Radiocarbon dates, Area D. Calibration was conducted using OxCal v4.1.7, using the IntCal09 calibration curve

\begin{tabular}{lllrrl} 
Lab no. & Material & Context & Date вр & $95 \%$ probability & $\begin{array}{l}\delta^{13} \text { C } \\
\% \text { oо }\end{array}$ \\
\hline UBA-13324 & Hazelnut shell & Fill of Post Hole 041 & $2985 \pm 26$ & $1374-1117$ вС & -25.7 \\
\hline UBA-13323 & Naked barley & Fill of Post Hole 041 & $2737 \pm 33$ & $967-819$ вС & -24.0 \\
\hline UBA-13326 & Hulled barley & Fill of Post Hole 058 & $2735 \pm 27$ & $927-818$ вС & -22.3 \\
\hline UBA-13327 & Hazelnut shell & Fill of Post Hole 058 & $2725 \pm 26$ & $921-813$ вС & -29.2 \\
\hline UBA-13325 & Wheat indet. & Fill of Post Hole 058 & $2630 \pm 29$ & $832-782$ вС & -22.2
\end{tabular}

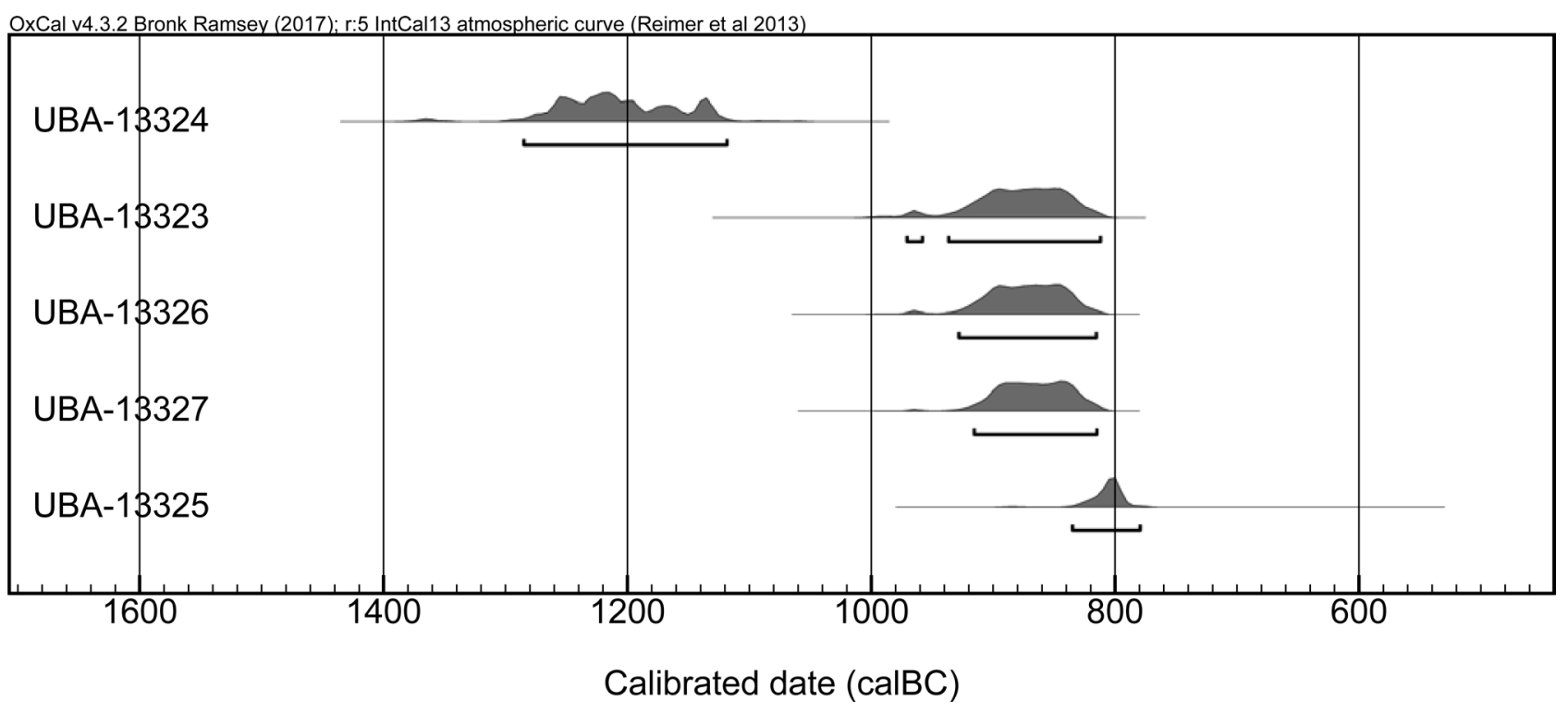

Illus 50 Radiocarbon dates, Area D 
Structure 1D, Linear Feature 086 and the group of pits to the south-east were all contemporary. However, Structure 1D appears to represent a singlephase structure.

\subsubsection{Architectural features of the structure}

The $11.5 \mathrm{~m}$ diameter of the structure is comparable to the LBA/EIA Structure 1F (Section 8).

Either of the ring grooves could have been the foundation for the outer skin of the structure. If 068 represented the position of the outer wall, then its proximity to the post ring may have meant that it was attached both to the post ring and secured in a foundation. If the outer ring groove represented the line of the outer wall, then the wall would have had to have been supported in some other way, by both the foundation slot and by posts, of which 015 may be a candidate. It is also possible that these two ring grooves represent two phases of building, 068 representing an earlier and heavily truncated structure.

The entrance faced the south-east, as did the majority of the structure entrances at Blackford. The entrance may have been framed by a small 'porch' or large door frame represented by Post Holes 027, 048, 018 and 035 .

The charcoal recovered from the features fits the overall pattern at Blackford of oak and hazel. The wood had been burnt but there was no evidence that the structure had burnt down, and the charcoal may then derive from other pyrotechnic processes such as a hearth.

\subsubsection{Structure use}

The post ring is thought to have been the foundations for a ring of upright posts for supporting a ring-beam and roof, and the entrance was framed. These architectural elements are suggestive of a structure designed for human use, rather than an animal stall, for example. The paucity of artefacts recovered from the structure did not allow conclusions to be drawn about what activities may have taken place within the structure. There was no evidence for a hearth, although Pits 098 and 033 occupied a position that made them likely candidates, and there was no evidence of crafted objects other than pottery for probable domestic use. The fact that domestic pottery was recovered from the contexts relating to the entrance, possibly derived from sweeping out the structure, is also supporting evidence for human use of the structure. On balance it is suggested that the structure was a house.

\subsubsection{Finds distribution and taphonomy}

Twenty-four sherds of pottery (131g) were recovered from three features, 024, 058 and 088. A total of $9.8 \mathrm{~g}$ of calcined bone was recovered from 13 features.

The bulk of the pottery, 96g, was recovered from the external pit, 088. A smaller quantity, 32g, was recovered from Features 024 and 058 in Structure $1 \mathrm{D}$, which were components of the entrance and may have acted as a refuse trap if the refuse was being swept from the structure.

\subsubsection{Economy}

This structure provided evidence for the first use of the hulled variety of barley on this site, which became the dominant species grown during the Iron Age in Scotland. The presence of wheat also suggests that this species was being grown. The calcined animal bone could theoretically have derived from either wild or domesticated species, and is likely to have been the waste product from a component of the house occupants' diet, as it was recovered from contexts that suggest the material had been caught up in the sweepings from the floor of the house.

The linear feature, although undated, is not thought to relate to modern agricultural drainage, as at its western arm it ran counter to the prevailing downslope landform. The feature was roughly aligned with a modern field boundary to the north, and may be a former land boundary. Its sinuous nature was reminiscent of the linear feature within Area $\mathrm{H}$ (Section 7), and the possibility that it was an old hedge line demarcating land divisions or fields should be considered. 